\title{
VERNACULAR SAUDI ARABIAN ARCHITECTURAL TECHNIQUES: REVIVAL TO MODERN SAUDI
}

\author{
SOHA MOHAMED-OBEID S. BINZAGR \\ Dar Al-Hekma University, Saudi Arabia
}

\begin{abstract}
This study is to reintroduce Jeddah's vernacular structures to a new communal residential building, which is a field that brings together individuals with common interest, that will help keep a connection of our heritage for future generations to come, as well as improve people's everyday lives. Traditional residential Hijaz building floor plans are constructed with multiple levels, consisting of several individuals from the same family. The research follows a triangular methodology: a questionnaire distributed among Jeddah city residence, case studies of modern communal building and a comparison between local and international buildings. Primary principles that affect spatial and architectural planning of present Saudi Arabian society are the socio-religious and cultural norms, although they have adapted to the changes of the 21 st century, privacy remains a key factor. This serves families that share the same values and/or economical aspects. This paper concludes with a proposal for a redefinition of design practices in Saudi Arabia within its cultural context; for today's architects and planners, only when a complete understanding of the socio-cultural as well as religious norms in present Saudi society are fully put into account, can a redefinition of Hijaz buildings be redefined to suit the present day Saudi families.
\end{abstract}

Keywords: modern architecture solutions, communal buildings, vernacular architecture, family structure, Jeddah, Saudi Arabia.

\section{INTRODUCTION}

This study is on how family structure; formed architectural buildings in Jeddah, Saudi Arabia's vernacular architecture. With an apartment building structure design, and how this can be translated to a communal residential structure for today's lifestyle and living conditions, to serve different families to coexist and contribute to each other as a support system.

The study starts by defining the residential building interior structure layout and the use of the spaces, and how it transformed over the years; and how this can be reintroduced today. As well as the difference between the communal residential buildings that is being suggested and the existing residential buildings that have shared common spaces and its true value for the residences. This research is within the western region of Saudi Arabia, Jeddah's urban city, old town (Al Balad), that is located on the coastline of the Red Sea. A climate that tends to be fairly the same throughout the year, its hot and humid.

With the move from traditional architecture of the Hijazi region of Jeddah, Saudi Arabia, an obvious neglect of passive techniques used in the past; were also overlooked and replaced; as well as the way people lived and interacted with each other. As new modern buildings with high technology were used; as well family structure of living, changed.

This thesis aims to redefine some of the abandoned methods to find its way back to our 21 st century buildings in an urban setting, to help keep a connection of our heritage for future generations to come, as well as improve people's lives through passive techniques and community inspired residential complexes. 


\subsection{Background of Jeddah}

In this part of the thesis, a summarized discussion of Saudi Arabia geographic, specifically the region of Hijaz. Analyzing the region will clarify the unique culture and environment of the Hijaz.

The Kingdom of Saudi Arabia (KSA) is known to be largest within the Arabian Peninsula in land mass through the Middle East. It is approximately made up of $\left(2,150,000 \mathrm{~km}^{2}\right)$, which is 95 percent desert, that includes Rub' Al Khali, the largest sand mass in all of the planet. Noticing the west coastline extends across $(1700 \mathrm{~km})$ of the Red Sea coast. With Saudi Arabia's strategic position, it played a great role in world trade [14], [16].

\subsection{Vision 2030}

As part of the vision 2030; is the conservation and preservation of the kingdom's heritage sites, Al Balad in Jeddah's old town is under UNSCO. Several cultural events took place in $\mathrm{Al}$ Balad in attempt to promote tourism locally and internationally.

\section{LITERATURE REVIEW}

The literature is divided into two sections: within the framework of both the social aspect and the design aspect, for traditional buildings in Hijaz 'Jeddah' and communal buildings 'local and 'international'. This is to get a better understanding of the form of vernacular structures in Jeddah, Saudi Arabia and how the form of the building affects the society as a community in Saudi.

\subsection{Communal structure}

As the residential complexes have shared common 'communal' spaces, it is noted that its residence uses these areas regularly. When compared to a compound design; these communal spaces, are used even more. On the other hand, low rise residential complexes, cater less to the concept of common spaces, and if available they tend to be small, which makes them unsuited to the tenants.

As one of the researches observed; the targeted age group that prefer communal residential complexes with a $77 \%$ participance, are between the ages of 25 to 34, within Jeddah, Saudi Arabia, with an $88 \%$ of them are married [3]. Although during 2010, the desired housing for young couples and small families was to own a villa or duplex, the views of the Saudi population shifted within these few years; now in 2019 people are leaning towards high to mid-rise complexes that cater to today's families lifestyle, with buildings that provide common amenities for its residence.

The preferred ideal size of apartments; has not changed from 2010, a three-bedroom unit with three bathrooms and two parking slots, is the most sought-after combination. As with the requested characteristics of any residential complex; people look for privacy, convenience, economical and outdoor environment that is family friendly. Even though, privacy is still a top precedence for the Saudi society, young families of today priorities safety, facilities and having a community to anything else [3], [4], [13].

\subsection{Social aspect}

A great impact on Saudi Arabian society; happened in the 1950's with the oil boom, a move from the vernacular architecture to adopting a contemporary westernized housing system within the three major regions in Saudi Arabia; the central, the eastern and the western. The 
rest of the kingdom had a change, but it was dominantly apparent in the main major regions, architecturally speaking.

With this move of modern, most of the buildings here in Jeddah, Saudi Arabia have lost their cultural identity. The urbanization; however, conceived a modern social living and lifestyle, with new policies and higher education standards, the society; as a whole, changed their way of thinking and priorities.

Taking all that into consideration, by applying the vernacular architectural elements, the use of passive techniques, not only as a beautifying iconic element; 'Rowshan'. This will contribute to the preservation of the Hijaz heritage, that coincides with the Crown Prince Mohammed Bin Salman's Vision 2030. The vision 2030, promotes and encourages local tourism, which facilitates in maintaining historical sites and protecting its importance to the culture. As a social aspect, that affects the architecture and urbanization of the community, other aspects of the vision 2030 play a major role like the entertainment section, which needs designers [2], [8], [9], [15].

\subsection{Design aspect}

As my topic is in the western region of Saudi Arabia, Al Hijaz, Jeddah city specifically; the climate is an important factor; when discussing design aspects, as well as the History of the architecture in the region. When the traditional architectural elements, structure, materials used are understood, its' implementation would be more accurate especially when trying to evolve the traditional designs to contemporary.

King [21] highlights the different materials used back in the day for construction, the coral blocks for instance is majorly used because of its availability from the Red Sea coast although its lack of decaying durability when exposed to humidity, other stones resembling the coral blocks might be a good alternative in contemporary structures. Plaster was used as a cover over Coral to protect it from humidity [5], [19], [21].

\subsection{Passive techniques}

Jeddah, Saudi Arabia in a warm-humid climate zone. Understanding the nature of our climate and the different architectural ways to sooth the heat is central. One of the best ways to cope with hot and humid weather conditions, are openness in the building and shading, with continues airflow a better ventilation and cooling system. As for shading, with less sun exposure, it would contribute to less heat absorption. And when comparing these elements with the ones used in old Hijazi architecture in Al Balad we can notice how they've considered and used passive ways for the dwellers needs, such as the Rowshan serving the ventilation and light flow to the interior of the building without forsaking the privacy factor.

As a ventilation method, other than the Rowshan and Mashrabiya, the staircase in the center is a wind catcher that covers the stairs underneath, with the staircase and Rowshan and Mashrabiya, this creates an airflow that enhances the buildings ventilation.

Hijaz buildings design features were created to cater to comfort the dwellers to suite their environment. Mashrabiya is used for both privacy and natural ventilation. These passive techniques: can be brought back, by using concert or steel systems for building structural system, additionally using local material for building elevation design, and adding passive cooling.

When linking communal complexes with energy efficiency; an $84 \%$ of the Saudi market responded positively as a desired combination for a residential housing. Which brings the passive techniques into light, and this generations education towards sustainability, energy 
efficiency and urbanized quality of life, that helps easy todays predicaments. Noting, this establishes that this thesis's concept is on track (Fig. 1) [2], [3], [6], [7].

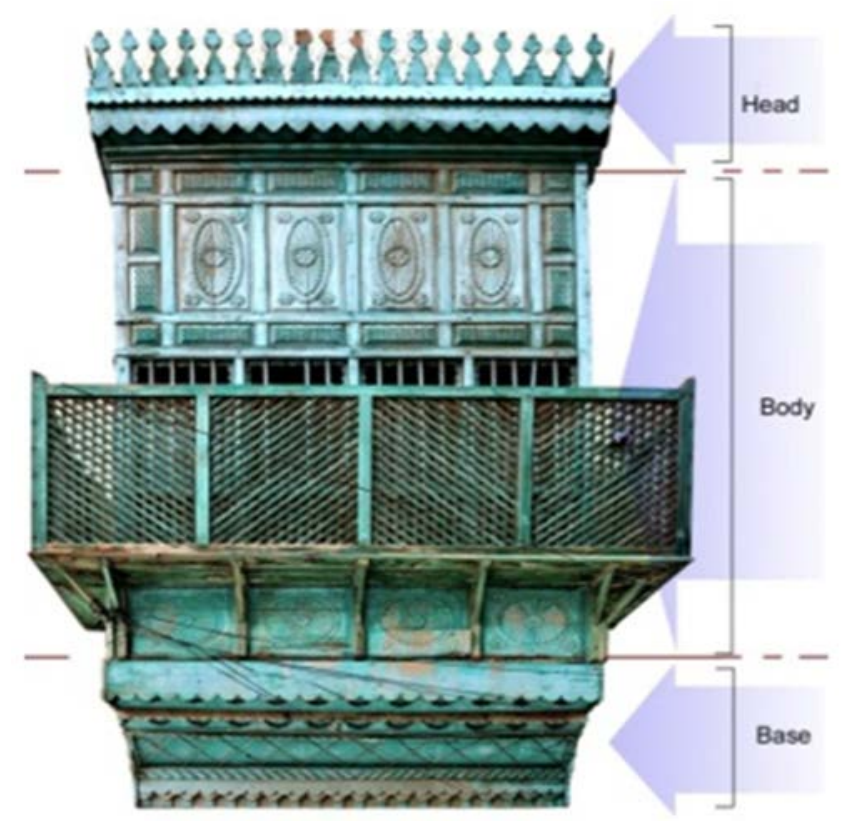

Figure 1: Roshan main parts. (Source: adopted from Alitani, 2011 [22].)

\subsection{Conclusion}

With the end of the literature review, it can be noted; that with the Vision 2030 that signifies a shift in society's views of ways of living, through different cultural experiences within the kingdom 'tourism' for example and the various entertainment, to name a few.

Architecture witness this shift, as both interior layout changes, as the family dynamic modified. As well as building facades have a more sustainable outlook.

A deeper insight, as this thesis analyzes the methodology by using the triangular method; of a survey, an interview with a real estate professional in Jeddah market and a thorough analysis of case studies that show case historical buildings of Jeddah and communal structures both local and international [15].

\section{METHODOLOGY}

This research will depend on a mixed qualitative method, triangular methodology 'Yin, Merriam, and Stake' [20], in a qualitative manner. And it will be collected as followed; a sample of 200 candidates, a questionnaire will be distributed among Jeddah city residence.

As well as an interview will be conducted with a real estate professional in the Saudi market. A sample of a modern communal building will be analyzed as a case study; through local structures and an international one as well. By noting logical issues within the region, as well as considering its application in new innovative form that serves the community without forgoing the Hijazi identity and ideology; that will be analyzed through a local vernacular Hejaz structure. 


\section{Survey Infographic}
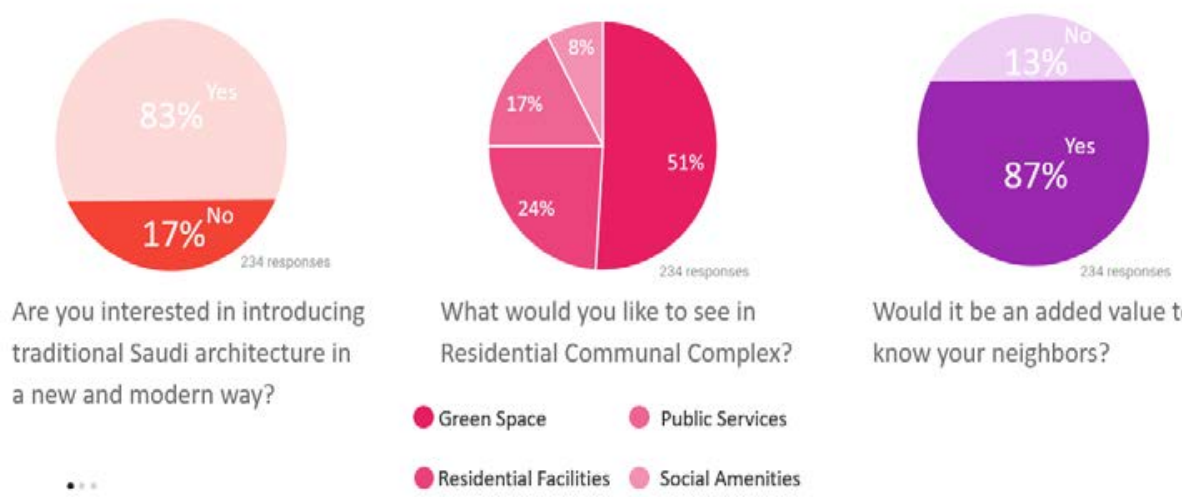

Would it be an added value to know your neighbors?

Figure 2: Survey results charts.

\section{PART 1 | SURVEY:}

A series of questions, with a response of 200 . That resulted in analyzing the community's response and need for a communal residence (Fig. 2).

\section{PART 2 | INTERVIEWS:}

Two interviews took place with professionals in the real estate industry.

\section{PART 3 | CASE STUDIES:}

An initial three cases were studied. A local traditional building from Al Balad in Jeddah. The second case; is a new local residential communal compound. The third is an international communal residential complex buildings case.

\subsection{PART 1 | SURVEY}

Reviving Saudi Arabian vernacular structure to new residential building, by redefining some of the abandoned methods to find its way back to our 21 st-century buildings in an urban setting. That will help keep a connection of our heritage for future generations to come, as well as improve people's lives through everyday additions, according to a survey distributed to just over 240 of Jeddah city residents. The results are shown in Tables $1-4$.

\subsubsection{Demographic characteristics}

Table 1: Gender (244 responses).

\begin{tabular}{|l|c|}
\hline Gender & Percentage (\%) \\
\hline Female & 77.5 \\
\hline Male & 22.5 \\
\hline
\end{tabular}


Table 2: Age (244 responses).

\begin{tabular}{|l|c|}
\hline Age & Percentage (\%) \\
\hline$<18$ & 0.8 \\
\hline $19-24$ & 6.9 \\
\hline $25-35$ & 41 \\
\hline $36-50$ & 45.9 \\
\hline$>51$ & 5.3 \\
\hline
\end{tabular}

Table 3: Number of people living in your house.

\begin{tabular}{|l|c|}
\hline No. of persons & Percentage (\%) \\
\hline$<2$ & 9.4 \\
\hline $3-4$ & 31.1 \\
\hline $5-6$ & 41.4 \\
\hline$>7$ & 18 \\
\hline
\end{tabular}

Table 4: Social status (number of people in the household).

\begin{tabular}{|l|c|}
\hline Social status & Percentage (\%) \\
\hline Single with no children & 23.7 \\
\hline Married with no children & 10.2 \\
\hline Divorced with children & 4.1 \\
\hline Married with children & 61.6 \\
\hline Divorced with the possibility of hosting children & 0.4 \\
\hline
\end{tabular}

\subsubsection{Acceptance}

Acceptance to an alternative living accommodation vs. the norm - the norm being that according to HMRC, 'examples of what is clearly living accommodation are houses, flats, houseboats, holiday villas and apartments. A compound (communal) living complex'. Types of housing are shown in Table 5 and experience with communal building is in Tables 6 and 7.

Table 5: Type of the house.

\begin{tabular}{|l|c|}
\hline Type & Percentage (\%) \\
\hline Villa & 52.9 \\
\hline Apartment & 29.5 \\
\hline Compound & 4.5 \\
\hline Duplex & 11.1 \\
\hline Shared house & 2 \\
\hline
\end{tabular}

Table 6: Knowledge of communal buildings (Have you heard about communal building?).

\begin{tabular}{|l|c|}
\hline Response & Percentage (\%) \\
\hline Yes & 46.3 \\
\hline I'm somewhat aware about communal building & 23.4 \\
\hline I'm completely unaware & 30.3 \\
\hline
\end{tabular}


Table 7: Household type (Are you living in a communal building or compound?).

\begin{tabular}{|l|c|}
\hline Response & Percentage (\%) \\
\hline Yes & 84.4 \\
\hline No & 15.6 \\
\hline
\end{tabular}

\subsection{Most important amenities for dwellers}

Amenities that are most desirable or useful features of facilities within a complex for dwellers. The result of the survey shows:

$45.3 \%$ of the respondents want the reception area, $56.4 \%$ wants gym, $42.4 \%$ wants cafe and restaurants, $79 \%$ want outdoor kids playing area, $42.4 \%$ wants gaming room, $63.4 \%$ wants multi-purpose hall.

There is controversy between the respondents when it comes to roof top pool $(28.8 \%$ passive respond), beauty salon (30.5\% passive respond), and home theatre (25.9\% passive respond).

\subsection{Revival of traditional architecture}

The social impact of traditional architecture within the community and their desire to bring back some elements from traditional Hijaz, in a way to suit the 21 st-century environment, are explored in Tables $8-11$.

Table 8: Are you interested in introducing traditional Saudi architecture in a new and modern way?

\begin{tabular}{|l|c|}
\hline Response & Percentage (\%) \\
\hline Yes & 83.6 \\
\hline No & 16.4 \\
\hline
\end{tabular}

Table 9: How would you like tradition Saudi architecture to be introduced?

\begin{tabular}{|l|c|}
\hline Object & No. responses \\
\hline Patterns & 137 \\
\hline Building layout & 16.4137 \\
\hline Principles & 81 \\
\hline Passive technique & 26 \\
\hline Trough acknowledgment great samples & 1 \\
\hline
\end{tabular}

Table 10: What would you like to see in residential communal complex?

\begin{tabular}{|l|c|}
\hline Object & Percentage (\%) \\
\hline Social amenities & 8.2 \\
\hline Recreational facilities & 23.9 \\
\hline Green spaces & 50.6 \\
\hline Public services & 17.3 \\
\hline
\end{tabular}


Table 11: Would it be an added value to know your neighbors?

\begin{tabular}{|l|c|}
\hline Response & Percentage (\%) \\
\hline Yes & 86.4 \\
\hline No & 13.6 \\
\hline
\end{tabular}

4 PART 1 | INTERVIEWS

\subsection{Brief}

An interview was conducted with the manager of sales in Abdul Lateef Jameel Land, which is the real estate department for architectural projects.

\subsubsection{Discussion}

A thorough analysis of both Gallery N, J|ONE and Dari Q projects were discussed from the motivation of 'Gallery $\mathrm{N}$ project', that has a modern Hijaz inspired architectural residential building, which coincides with this thesis's hypothesis.

As the real estate professional indicated, that young Saudi families, changed the interior layout with the shift in lifestyle, the concept of segregation within the home but rather the desire to enjoy the house fully with an open space layout is the majority's wish. He reveals as well that the move from the dream of owning a villa to owning an apartment; that people are yearning for a community; this point proves that this thesis's topic for reintroducing communal buildings is with Saudis' new direction. The Gallery N project although it was not a communal building, but the design was based on a Hijaz inspired concept, which confirms this thesis's aspiration for reintroducing some of the Hijaz traditional architectural designs and passive techniques.

\subsection{PART 2 | INTERVIEW}

\subsubsection{Brief}

An interview was conducted with one of the tenants from Al Balad buildings, during the 1960s.

\subsubsection{Discussion}

A better understanding of daily life in Al Balad during the 1960s, especially for women. Although there was a freedom to roam the street and shop as well as get an education, there were still a bit of segregation in the home. Al Magad, is an area of the house were meant for men of the family and their guests. It was a similar life where small things gave joy, like sitting on the Rowshan and looking though to people doing their routine. Within the house there were day the heat got unbearable, all family members slept on the roof, but there was a breeze throughout the house usually.

\section{PART 3 | CASE STUDY}

\subsection{Communal Building Case Study - International Coop Housing at River Spreefeld}

\subsubsection{Brief}

Spreefeld/River Spreefeld located in Berlin, Germany with an area of 7400 square meter was done by 2013. This communal complex is called Baugruppen in German for 'building group', which stands for a long tradition of self-initiated, community-oriented living and 
the shared responsibility of building. The self-initiated housing is a cooperative housing, that is a safe alternative and affordable of shared ownership through a sustainable housing settlement that is integrated into the neighborhood. The project has a clear distinction between private, communal, and public spaces.

The idea of arranging the different programs within each building; standard flat, communal space, commercial units, communal terraces, cluster units, is a great organization of identification and noticeably clear in (Fig. 3) with the color coding.

\section{PROGRAM INTERIOR}
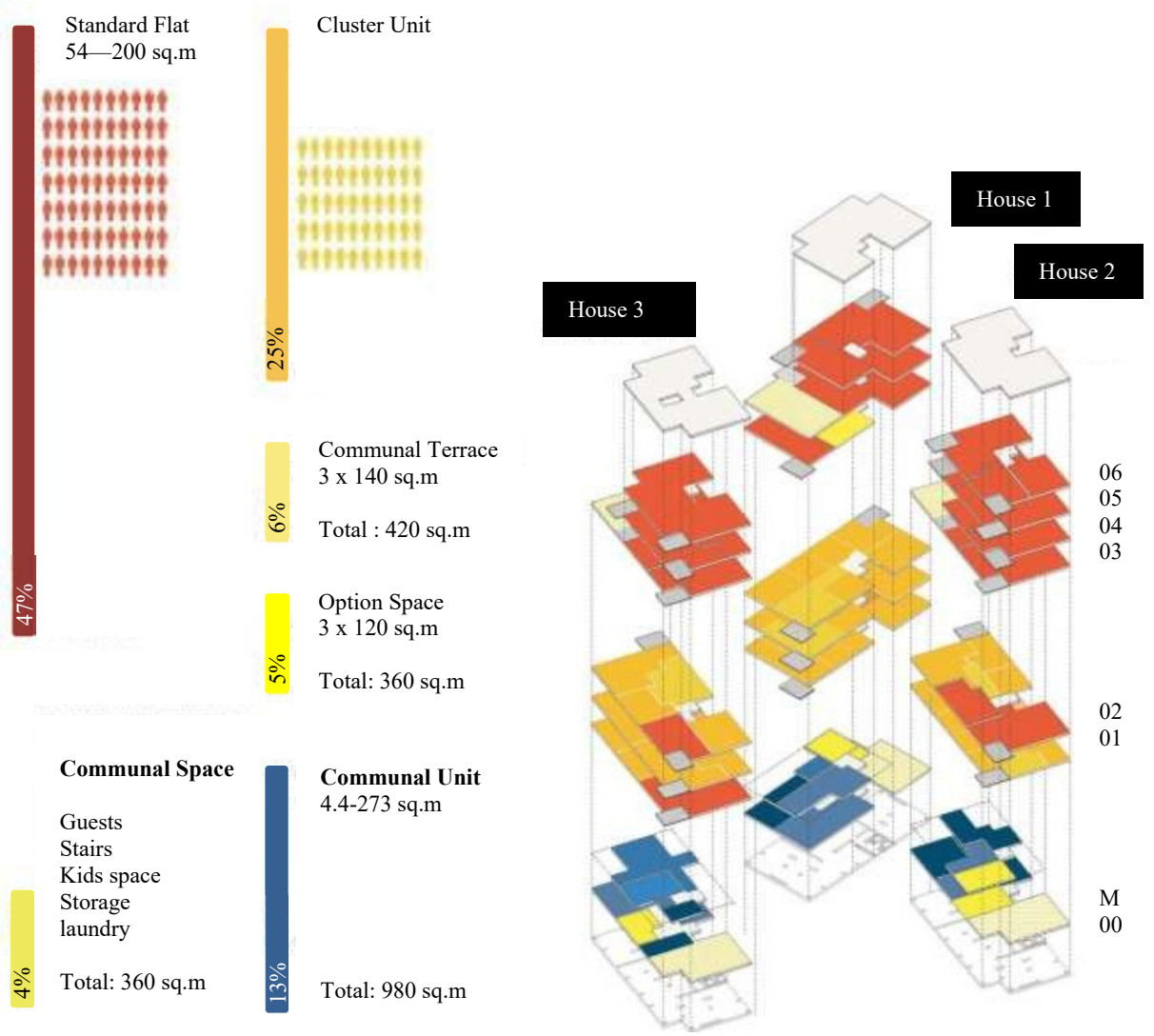

Figure 3: Interior organization of each building in the River Spreefeld complex.

\subsubsection{Discussion}

Unfortunately, this was a failed project. Many of such communal building complexes in Berlin, Germany were abandoned and then demolished. There was a security issue for the tenants, that got addressed with a gated compound complex.

As the benefits from this case, the way the tenants addressed their needs for the architectural layouts made them feel more at home as well as a sense of ownership. With the many common area, a sense of community helps the dwellers as a support system. Also, with 
area like the daycare center helps in building a stronger society. The public areas were for rent, that created revenue for the complex [10], [12], [17], [18].

\subsection{Old Jeddah Buildings Case Study - Local Baeshen House}

\subsubsection{Brief}

Baeshen House is in 'AL Bald' the old town of Jeddah, Saudi Arabia, with a Hijaz architectural style. Almost all the Hijaz vernacular residential buildings have an apartment style structure that coincides with the communal building living. It has been neglected in recent years, as urbanization and the change in family dynamics. Location: Geography of Baeshen House within Al Balad).

\subsubsection{Cooling}

Cross-ventilation in the main method for cooling that is used in Baeshen House. There are several openings on the façade, as well as in the interior walls to permit the air to flow through (Fig. 4). Air is highly valued as it cools down the interior spaces substantially during summer hot days. The height of the house was a sheer effect to the seasonal breeze in Jeddah. The bedrooms were places on the top floors, to easily produce on-shore and off-shore winds blowing at high altitudes (Fig. 5). Staircase shaft is in Jeddah's typical houses, which allows the hot air to rise and escape out of the building. The staircase is located near the center of the building (Fig. 6).

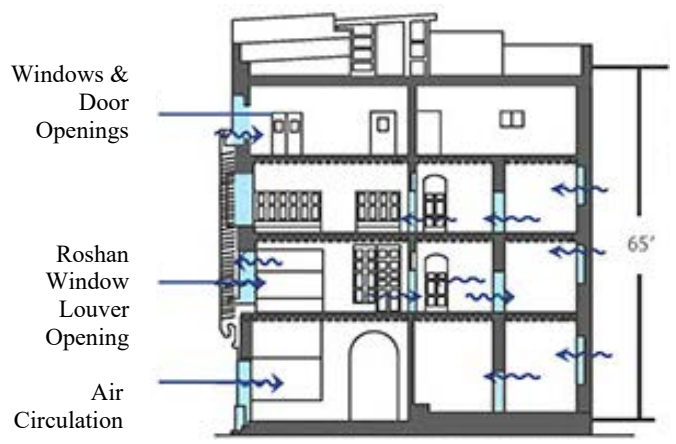

Figure 4: Cross-ventilation.

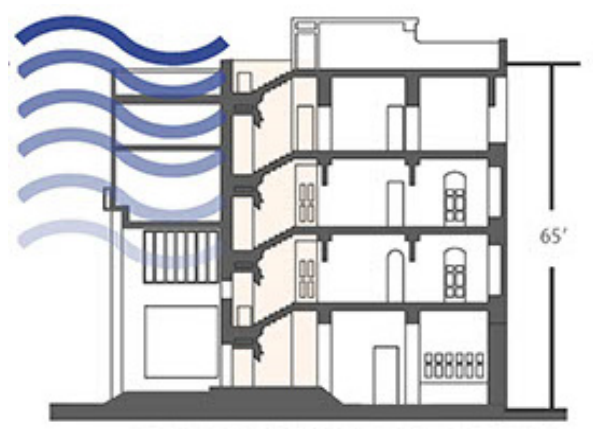

Figure 5: High-altitude breeze. 


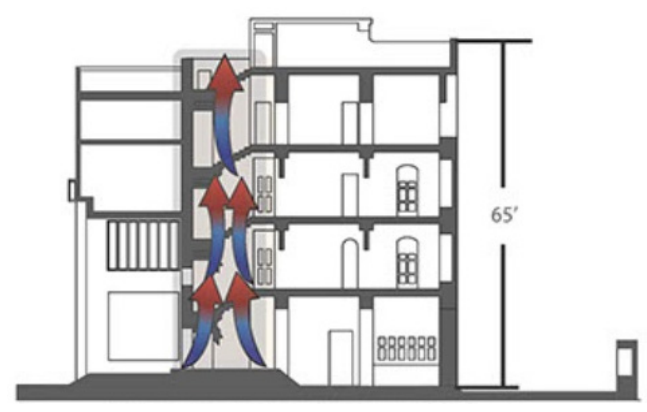

Figure 6: Ventilation shaft.

\subsubsection{Shading}

Jeddah heat source is mostly from the sun. As unwanted heat is gained in interior areas of the house, shading helps in retaining daylight without the heat. Roshans helped reduce the heat gain by shading the exterior walls of the façade openings, in addition to providing indirect sun light into the interior space (Fig. 7).

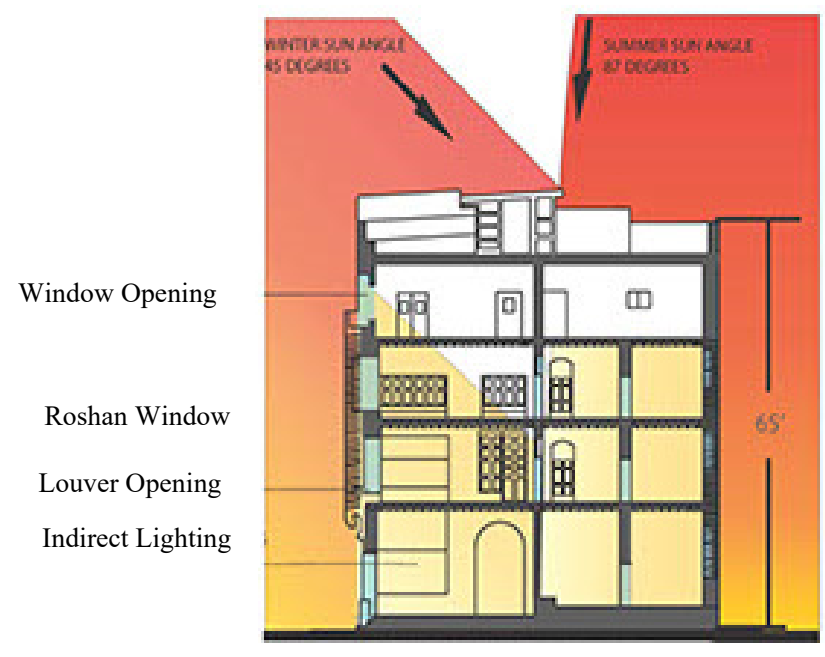

Figure 7: Cross section showing daylight.

The Rowshan; contains many thin wooden strips intricately jigs awed together. The pattern difference is an indication of the function of the allocated space it covers. For example, horizontal louvers are for bedrooms to maximize privacy, a more Islamic decorative pattern is assigned for guest reception Rowshan.

\subsubsection{Discussion}

When discussing the passive techniques used, from climate control with simple tactics, for example, the cross ventilation through several openings within the exterior and interior of the structure. Roshans helped reduce the heat gain by shading the exterior walls of the façade openings, in addition to providing indirect sun light into the interior space [1], [7]. 
5.3 Residential Compound Complex Case Study_Local J|ONE (Abdul Lateef Jameel Land).

\subsubsection{Brief}

A high-quality home tailored to the needs of urban individuals and families, with a 64,000 sqm vertical apartment complex; J|ONE's eco-friendly facilities including outdoor pools, a health club, home theatre, café, gaming room, day-care nursery and mini market.

\subsubsection{Discussion}

This case study is a great example for a compound as a communal complex with different common facilities for all $\mathrm{J} \mid \mathrm{ONE}$ residence. It is a gated compound community, which provides security and privacy from non-residence. Cons noticed in this case study, are the facilities marketed are difficult to maintain, and as such there isn't a mini market in the complex yet; although with more tenants the promise is that all the earlier amenities discussed will be present. As for the pros; there's a great deal with all the landscaping available, children playgrounds, outdoor pool, gaming room and daycare center, just to name a few of the amenities available [11].

\subsection{Comparison}

A comparison between the three case studies is shown in Table 12.

Table 12: Comparison of the case studies.

\begin{tabular}{|l|c|c|c|}
\hline KPI'S & Case Study 1 & Case Study 2 & Case Study 3 \\
\hline Safety/security & $\mathbf{X}$ & \\
\hline Privacy & & & \\
\hline Landscaping & & & \\
\hline Facilities & & & \\
\hline $\begin{array}{l}\text { Vernacular } \\
\text { design }\end{array}$ & & & \\
\hline $\begin{array}{l}\text { Contemporary } \\
\text { design }\end{array}$ & & & \\
\hline
\end{tabular}

\subsection{Conclusion}

The three case studies previously discussed, benefit this thesis, by grasping the pros and cos of the two communal complexes mentioned. And comparing the findings to the vernacular Hijaz structure in terms of design and as a social factor.

Also, addressing the issue of how to positively improve Saudi Arabian residence ease their lives by designing a more eco-friendly, sustainable building with the support of passive techniques learnt from Hijaz structures. 


\section{REFERENCES}

[1] Abu-Ghazzeh, T.M., Domestic buildings and the use of space: Al-alkhalaf fortified houses-Saudi arabia. Vernacular Architecture, 26(1), 1-17, 1995.

[2] Abu-Ghazzeh, T.M., Privacy as the basis of architectural planning in the Islamic culture of Saudi Arabia. Faith and the Built Environment: Architecture and Behavior in Islamic Cultures, Vol. 11(3), pp. 269-287, 1996.

[3] Abuazzah, M.M., Residential Real Estate Project in Saudi Arabia Developing an Upscale, Modern, and Innovative Residential Real Estate Project in Saudi Arabia, The Johns Hopkins Carey Business School, Vol. 9, 2010. https://doi.org/10.1558/jsrnc.v4il.24

[4] Adas, Y.A., Change in Identity of Saudis' Built Environments: The Case of Jeddah. $\mathrm{PhD}$ thesis, February 2001.

[5] Al-Ban, A.Z.G., Architecture and cultural identity in the traditional homes of Jeddah. IOSR Journal of Economics and Finance, 3(1), p. 56, 2016.

[6] Al-Lyaly, S.M.Z., The traditional house of Jeddah: a study of the interaction between climate, form and living patterns. PhD dissertation, University of Edinburgh, 1990.

[7] Alsaggaf, F., Jeddah Coral Dwelling: Baeshen House: Case Study on Behance.

[8] Bowen, W.H., The history of Saudi Arabia. Choice Reviews Online, 36(07), pp. 364062, 1999.

[9] Paciello, M.C., Basosi, D. \& Violi, S., Saudi Arabia Faced with Modernity: from the Demographic Transition to 'Vision 2030', 2016.

[10] Coop Housing at River Spreefeld/Carpaneto Architekten + Fatkoehl Architekten + BARarchitekten, (n.d.). https://www.archdaily.com/587590/coop-housing-project-atthe-river-spreefeld-carpaneto-architekten-fatkoehl-architekten-bararchitekten.

[11] J|ONE Residence (n.d.).

[12] Khamis, S., Berlin, A Selfmade Culture - Future-Oriented Self-Initiated Co-Housing and Residential Projects, September 2017.

[13] Mahdavinejad, M., Mashayekhi, M. \& Ghaedi, A., Designing communal spaces in residential complexes. Procedia - Social and Behavioral Sciences, 51, pp. 333-339, 2012.

[14] Mortada, H., Architectural \& Urban Distinctions of Historic Jeddah, Saudi Arabia, 2014.

[15] Quality of Life Program, Quality of Life Program 2020: Delivery Plan, pp. 1-236, 2018. https://vision2030.gov.sa/en/qol.

[16] Saudi_Arabia, (n.d.).

[17] Schwarz, S. \& Sabatier-Schwarz, I., Self-organised urban space without profit: Four Examples in Berlin. plaNext - next generation planning, 5: 78-90, 2017.

[18] spreefeld-co-housing, (n.d.).

[19] Mileto, C., Vegas, F., García Soriano, L. \& Cristini, V., Vernacular Architecture: Towards a Sustainable Future, CRC Press: London, 2014.

[20] Yazan, B., Three approaches to case study methods in education: Yin, Merriam, and Stake. Journal of Automated Reasoning, 20(2), pp. 207-233, 2015.

[21] King. G., The Traditional Architecture of Saudi Arabia, IB (London): London, 1998. https://eprints.soas.ac.uk/id/eprint/463.

[22] Alitany, A., Rebondo, E. \& Adas, A., The 3rd documentation of projected wooden windows (the Roshan) in the old city of Jeddah (Saudi Arabia) using image-based techniques. ISPRS Annals of the Photogrammetry, Remote Sensing and Spatial Information Science, 2(5/W1), pp. 79-84, 2013. 